International Journal of Linguistics, Literature and Culture
Available online at https://sloap.org/journals/index.php/ijllc/
Vol. 5, No. 4, July 2019, pages: 19 24
ISSN: 2455-8028
https://doi.org/10.21744/ijllc.v5n4.686

\title{
Profile of Relative Strength Among Various Weight Categories of Senior National Women Weightlifters
}

V. F. Peter ${ }^{\text {a }}$

Suhel Raza ${ }^{b}$

Article history:

Received: 09 March 2019

Accepted: 31 May 2019

Published: 31 July 2019

\section{Keywords:}

relative strength;

mangalore;

senior national;

weightlifting;

women;

\begin{abstract}
\end{abstract}
The purpose of this study was purposively selected from the "Senior National Championship for the year 2018. Only women weightlifters participated in various weight categories, acted as the subjects. The age of the subjects ranged from 18-34 years. The total subjects were $\mathbf{N = 5 4}$, which were divided into three (3) groups of eighteen (18) subjects for each group. The first groups were low weight categories ( $48 \mathrm{~kg}$. \& $53 \mathrm{~kg}$.), Second groups were middleweight categories $(63 \mathrm{~kg}, 69 \mathrm{~kg}$.) and third groups were upper group weight categories $(90 \mathrm{~kg},+90 \mathrm{~kg}$.). In order to measure the relative strength of various lifters of different groups, the data was collected from the results of "Senior National Championship" Mangalore, Karnataka $21^{\text {st }}$ to 25 January 2018. Descriptive Statistic (Mean, Standard Deviation), One-way, ANOVA (Analysis of variance) with post hoc test (LSD) was applied to analyze and compare the relative strength among the different body weight categories. The level of significance was set at 0.05 .3 indicate that there were significant differences in the entire three groups. However, group Lower had higher relative strength. After applying the post Hoc Test (LSD) it was found that there was a significant difference in all three groups in their relative strength.

2455-8028 ${ }^{\circ}$ Copyright 2019. The Author. This is an open-access article under the CC BY-SA license (https://creativecommons.org/licenses/by-sa/4.0/) All rights reserved.

\section{Author correspondence:}

Peter, V. F.

School of Physical Education DAVV, Indore, India.

Email address: peterfrancis71@gmail.com

\section{Introduction}

The sport or activity of lifting barbells or other heavyweights. There are two standard lifts in modern weightlifting: the single-movement lift from floor to extended position (the snatch), and the two-movement lift from floor to shoulder position, and from shoulders to extended position (the clean and jerk) https://youtu.be/KT4YHc06kmQ

${ }^{\text {a }}$ School of Physical Education DAVV, Indore, India

${ }^{\mathrm{b}}$ Chatrapati Sahuji Maharaj University, Kanpur, India 
Relative strength is an aspect of fitness that we focus on as opposed to simply strength in general. Relative strength is the strength of an individual in relation to their body weight. It's easy to be strong and huge, but this does not always serve the most efficient function. This sort of strength development means being super strong for your size (Hooks, 1962; Loy et al., 1978).

You have to appreciate competition...whether it's in sport, exercise, the workplace, or any other facet of life, competition is the driving force behind greatness. At an evolutionary level, it is what is responsible for the advancement of humankind. Competitions for resources, for power, and for wealth have been the catalysts for all of the great leaps in human civilization. Today we'll be looking at one of the oldest and most basic physiological forms of competition....strength.

For thousands of years, man has been testing his strength against others. Going back to the ancient Olympic games, human beings have always valued the accumulation and development of raw physical power. But how do we judge how strong a person really is? Today, I'll be explaining the advantages, disadvantages, and differences between the two types of strength, absolute and relative. First, we will start with some basic definitions (Mann, 1967).

Absolute strength is the type of strength the average person is most familiar with. Anyone who has spent any time in a gym has certainly been asked, "How much do you bench?" or "How much can you squat?" These questions refer to absolute strength, or, the maximum amount of force that someone can exert, irrespective of body size or weight. This type of strength is best measured with 1-rep maximum calculations in different weight training movements (i.e. max bench, max squat, max clean).

Relative strength is just what it sounds like....the maximum amount of force that someone can exert in relation to body size or weight. Relative strength is commonly measured with bodyweight exercises such as pushup and pullups. However, these types of measure are not always accurate as they sometimes measure muscular endurance as opposed to power. For this reason, it is more accurate to use a measure of 1RM and then compare it on a scale of body weight, or use a maximum athletic effort such as the 40-yard dash or high jump (O'Shea, 1976; Singh, 1984).

To make the comparison a little easier, I will use an example. Let's take two athletes...Athlete 1 weighs 150 pounds, can bench press 200 pounds, and can squat 300 pounds. Athlete 2 weighs 200 pounds, can bench press 250 pounds and can squat 350 pounds. So Athlete 2 is stronger right? Well, sort of....Athlete 2 does have greater absolute strength, but Athlete 1 actually has greater relative strength (A1 can bench press 1.33 times his weight and squat 2 times his weight while A2 can only bench 1.25 times his weight and squat 1.75 times his weight). So you can see that the "strongest" person is not always the one who can lift the most weight!

https://absolutefitonline.wordpress.com/2011/12/01/how-strong-are-you-really-absolute-vs-relative-strength/

Doncash et al., (1956) by environment human beings are competitive and aspire from excellence in every field. Sport is not an exception, changes are the order of the day. Changes are taking place each day in every walk of life. Life of people, their philosophy, ways of living, etc. are undergoing changes due to basic and applied research in various fields. Man has reached the space age from the primitive "Stone Age" because of continuous changes. Records have been sprucing as a result of combined improvement in the technique of training and coaching. New techniques are established in laboratories and scientific methods are applied to obtain the level of performance. Sports by their very nature are enjoyable, challenging, absorbing and require a certain amount of skill and physical condition. Bucher Today we all know that now a day is an area of smallest input and extreme output and for this, every possible work is being done to increase efficiency. Every perception angle is being thoroughly scrutinized by researchers and scientists together so that sportsmen can get maximum mechanical advantages to improve their performance, the clear insight of sports during Greek period was reflected in the Epic poems of Homer. Games were part of the daily life of the people or any important event. C.N. Gardiner (1955), Games and sports are a popular pastime activity for the young and the old, for boys and girls and for men and women. They offer an opportunity for all to obtain exercise, fun, and relaxation. They can play an important role in developing physical fitness and skills for use in leisure time, now and perhaps more importantly, in later years. Many of the skill developed thought games and sports may be used in years to come to help keep physically fit. Strength training has made the single, most positive contribution to this type of improvement (Bosworth, 1964; Clarke, 1954). Witness the performance this year of tennis ace Serena Williams and Giants Slugger Barry Bonds. Maximum strength is the backbone upon which all other strength qualities depend. You'll hear me talk a lot about being fast and the importance of speed, power, reactive ability, etc. 
Objectives of the study

To compare the relative strength among the different weight categories groups of women weightlifters of senior national championship Mangalore, Karnataka, India.

\section{Materials and Methods}

The purpose of this study was purposively selected from the "Senior National Championship" Mangalore, Karnataka $21^{\text {st }}$ to 25 January 2018. Only women weightlifters participated in various weight categories, acted as the subjects. The age of the subjects ranged from 18-32 years. The total subjects were fifty-four $(\mathrm{N}=54)$, which were divided into three (3) groups of eighteen (18) subject for each group. The first groups were low weight categories (48 $\mathrm{kg}, 53 \mathrm{~kg}$.), Second groups were middleweight categories $(63 \mathrm{~kg}, 69 \mathrm{~kg})$ and the third group was upper weight categories $(90 \mathrm{~kg},+90 \mathrm{~kg}$.)

Instrument Reliability: All the instruments and equipment like weighing machine, Bar, Weight plates, collars, platform, and outfits were taken.

Testers Reliability: Since the data's for the study is taken from the performance of "Senior National weightlifting Championship" for Mangalore, Karnataka $21^{\text {st }}$ to 25 January 2018 and was conducted by the qualified National and International referees, these scores were assumed to have a higher level of reliability.

Collection of Data: In order to measure the relative strength of various lifters of different groups, the data was collected from the results of "Senior National weightlifting Championship" which was held at Mangalore, Karnataka $21^{\text {st }}$ to 25 January 2018 . The sum of the best lifts snatch and cline $\&$ jerk total of respective events was considered as the scores of the lifters.

\section{Statistical Analysis}

According to the objectives of the study to gathering the data Analysis of descriptive statistics were used. (Mean Standard Deviation)

One-way Analysis of variance (ANOVA) was applied to analyze and compare of the relative strength among the various weight categories groups of Senior National weightlifting Championship" which was held at Mangalore, Karnataka $21^{\text {st }}$ to 25 January 2018. The level of significance was set at 0.05

\section{Results and Discussions}

\section{Findings}

The total subjects were fifty-four $(\mathrm{N}=54)$, which were divided into three groups of eighteen 18 subjects each equal subjects. The sum of the one best snatch lift and one clean \& jerk lift of each event was considered as the scores of the lifters. The mean and standard deviation values of all the three groups lover, middle and upper. The results pertaining to the study are present with the help of following tables and Graphs.

Table 1

Mean and Standard Deviation of Scores of the Relative Strength of Lifters From various Weight category Groups)

\begin{tabular}{llll}
\hline Weight Category Groups & N & M & SD \\
\hline Lower Group & 18 & 3.3215 & .37540 \\
Middle Group & 18 & 2.9468 & .25483 \\
Upper Group & 18 & 2.0182 & .32540 \\
Total & 54 & 2.7622 & .63704 \\
\hline
\end{tabular}

Peter, V. F., \& Raza, S. (2019). Profile of relative strength among various weight categories of senior national women weightlifters. International Journal of Linguistics, Literature and Culture, 5(4), 19-24. 


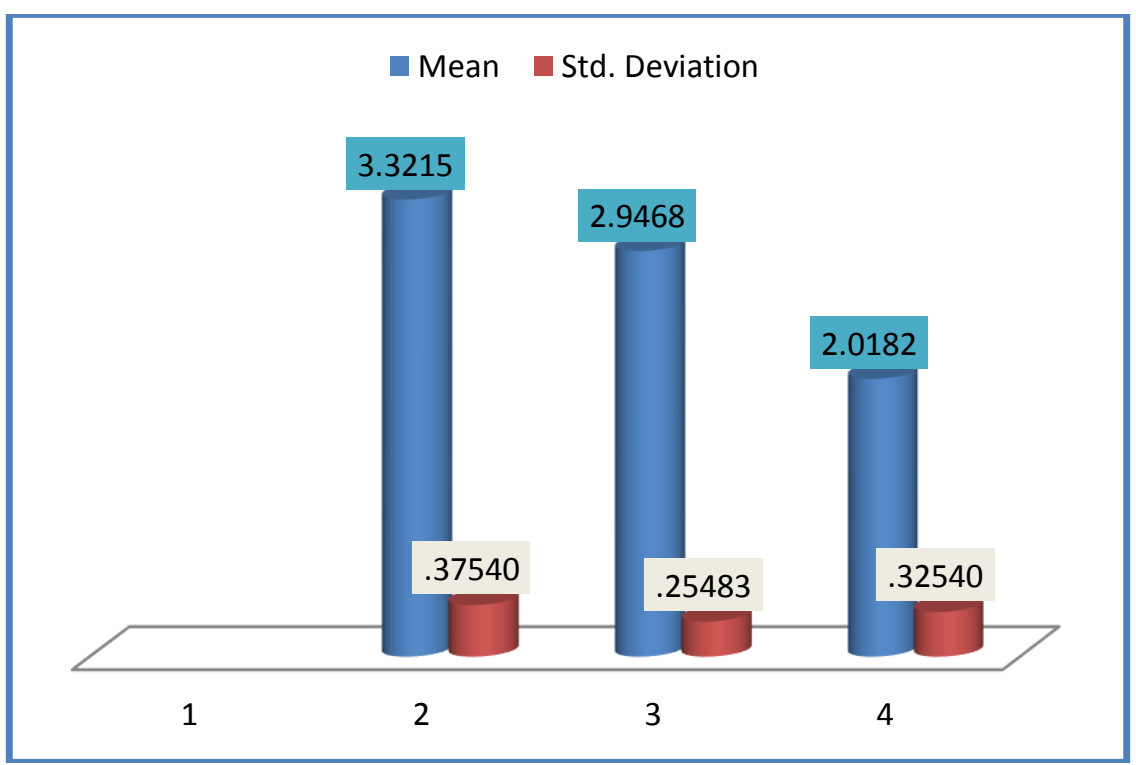

Table 2

ANOVA

\begin{tabular}{llllll}
\hline Source of variance & $\begin{array}{l}\text { Sum of } \\
\text { Squares }\end{array}$ & $\begin{array}{l}\text { Mean } \\
\text { Square }\end{array}$ & Df & F & \multirow{2}{*}{ Sig. } \\
\hline Between Groups & 16.209 & 8.105 & 2 & 77.991 & .000 \\
Within Groups & 5.300 & .104 & 51 & & \\
Total & 21.509 & & 53 & & \\
\hline
\end{tabular}

Table 3

Critical Mean Difference Table

\begin{tabular}{|c|c|c|c|c|c|}
\hline $\mathrm{S}$ & \multicolumn{3}{|c|}{ GROUP MEAN } & \multirow[t]{2}{*}{ MD } & \multirow[t]{2}{*}{$\mathrm{CD}$} \\
\hline $\mathrm{N}$ & Low & Middle & Upper & & \\
\hline 1 & 3.32 & 2.94 & $-\cdots$ & .37474 & $\overline{0.214}$ \\
\hline 2 & 3.32 & ------- & 2.01 & 1.30336 & \\
\hline 3 & ----- & 2.94 & 2.01 & .92862 & \\
\hline
\end{tabular}

Table 3 reveals that the mean value of relative strength of lower group weight category (48kg- $53 \mathrm{~kg})(3.32)$ and middle group weight category $(63 \mathrm{~kg}-69 \mathrm{~kg})(2.94)$ mean difference value is $\mathbf{. 3 7 4 7 4} *$ and critical mean difference value (0.214) and between lower group weight category (48kg- 53kg) (3.32) and upper group weight category (90kg+90 kg) (2.01) mean difference value $\mathbf{1 . 3 0 3 3 6}$ and critical difference value $(0.214$ which was more than critical difference value therefore it is concluded that there is a significant difference between the lower group and middle group, lower and upper group weight category.

The mean value of middle group weight category (63kg- $69 \mathrm{~kg})(2.94)$ and lower group weight category (48kg, $53 \mathrm{~kg}$ ) (3.32), mean difference value is $\mathbf{- 3 7 4 7 4}$ critical mean difference value (0.214). And Between middle group weight category (2.94) and upper group weight category (2.01), the mean difference value is $\mathbf{1 . 3 0 3 0 6}$ critical difference value (0.214) Hence it is concluded that there is a significant difference between the groups,

The mean value of the upper group weight category (2.01) and lower group weight category (3.32), the mean difference value is $\mathbf{1 . 3 0 3 3 6}$ and critical mean difference value (0.214). And Between upper group weight category 
(2.01) and middle group weight category (2.94) mean difference value is $\mathbf{9 2 8 6 2}$ critical difference value (0.214). Therefore, it is concluded that there is a significant difference between the groups.

\section{Conclusion}

The analysis of the data was obtained value of " $F$ " $\mathbf{7 7 . 9 9 1}$ and tabulated value is $\mathbf{3 . 1 7}$ from table 2 is statistically significant at 0.05 levels. $\mathrm{F}$ value is found significant because the calculated value is more than tabulated value. Subsequent to the finding of significant $\mathrm{F}$ value, it is indicated that there are significant mean differences between all three groups of senior national women weightlifters of Relative strength. After applying the post Hoc Test (LSD test) it was found that there was a significant difference in the entire 3 groups in their relative strength. Group-I had the highest relative strength as its mean value is highest among all the groups. "Senior National weightlifting Championship" which was held at Mangalore, Karnataka $21^{\text {st }}$ to 25 January 2018 . This may be probably due to the different nature of training and pre-requisite components for lifters. Such results may be due to the small size of the sample and other factors such as different body types, muscular ability, aging factors and the difference in the body compositions, etc.

Conflict of interest statement and funding sources

The authors declared that they have no competing interest.

\section{Statement of authorship}

The authors have a responsibility for the conception and design of the study. The authors have approved the final article.

\section{Acknowledgments}

The authors would like to thank the editor team of IJLLC for their valuable time, support, and advice in completing the current article.

Peter, V. F., \& Raza, S. (2019). Profile of relative strength among various weight categories of senior national women weightlifters. International Journal of Linguistics, Literature and Culture, 5(4), 19-24. 


\section{References}

Bosworth, J. M. (1964). Relationships between the vertical jump performance of college women and selected anthropometric measurements and strength variables (Doctoral dissertation, Springfield College).

Bucher, C. A. (1979). Fundamental of Physical Education.

Clarke, H. H. (1954). Relationship of strength and anthropometric measures to various arm strength criteria. Research Quarterly. American Association for Health, Physical Education and Recreation, 25(2), 134143.

Doncash, S. (1956). Basic Book of Sports. Englewood Cliffs, N. J: Prentice Hall, Inc, 1.

Gardiner, E. N. (2002). Athletics in the ancient world. Courier Corporation.

Hooks, G. (1962). Application of weight training to athletics. Prentice Hall.

Loy, J. W., McPherson, B. D., \& Kenyon, G. S. (1978). Sport and social systems: A guide to the analysis, problems, and literature. Addison Wesley Publishing Company.

Mann, D. A. (1967). The relationship of toe strength and flexibility to free-running speed (Doctoral dissertation, Central Missouri State College).

O'Shea, P. (1976). Scientific principles and methods of strength fitness. Addison Wesley publishing company.

Singh, H. (1984). Sports training: general theory \& methods. Netaji Subhas. Nat. Inst. of Sports.

\section{Biography of Author}

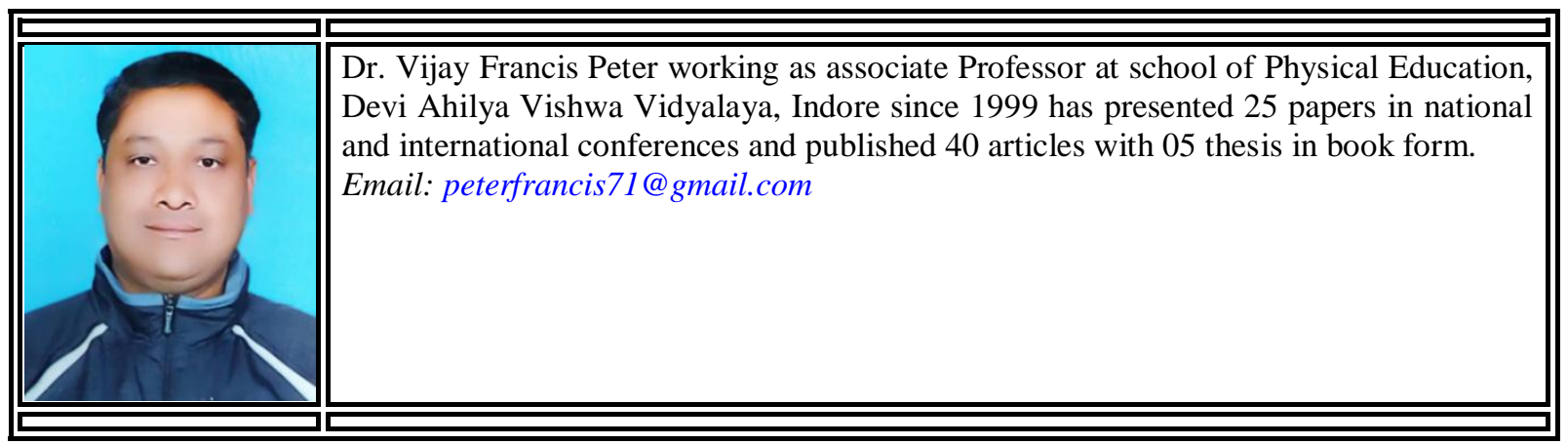

